\title{
GESTÃO DE CARREIRA: UM ESTUDO DA PRODUÇÃO CIENTÍFICA NOS PERIÓDICOS
}

\section{BRASILEIROS}

\author{
Career Management: Scientific Production Study in Brasilian Journals
}

Tamiles Provenzi ${ }^{1}$

Rosiane Oswald Flach ${ }^{2}$

Recebido em: Aceito em:

Resumo: O objetivo deste artigo é delinear o perfil da produção científica do tema gestão de carreira nos artigos publicados nas bases de dados Spell e Scielo, buscando compreender o perfil e tendências do campo a partir da produção científica sobre o tema. Realizou-se uma pesquisa descritiva com abordagem qualitativa, a qual utilizou as estratégias de levantamento e de Bibliometria, por meio de uma Revisão Sistemática. A amostra contou 95 artigos. Os resultados apontam que 2014 foi o ano com maior número de publicação, destacando o papel dos autores: Joel Souza Dutra, Elza Fátima Veloso, Leonardo Nelmi Trevisan e Dione Fagundes Nunes Gomes. Há predominância de autores do gênero feminino (58,17\%). A Universidade de São Paulo (USP) compõe o 'core' no cenário nacional, com dezesseis artigos vinculados. A Revista ReCaPe (Revista de Carreira e Pessoas) foi a que mais publicou, com onze (11) trabalhos. Os estudos qualitativos se destacaram (43,02\%), sendo que as principais áreas de interesse de publicação dos autores foram: Carreiras, Gestão de Pessoas, Trabalho e Competências. Para indicações futuras, sugerem-se estudos que abordam a preparação de, retenção de talentos, valorização e crescimento profissional, âncoras de carreira, geração " $Y$ " e estudos na gestão pública. Como considerações finais são apresentadas as principais análises, limitações e a sugestão de que o presente trabalho possui competência para ser instrumento de novos estudos.

Palavras-Chave: Gestão de Carreira. Revisão Sistemática. Produção Científica.

Abstract: This article's goal is to outline the scientific production profile about Career Management in articles published in Spell and Scielo databases, seeking to understand the profile and trends from the scientific production on the subject. A descriptive research with a qualitative approach was carried out, which used survey and Bibliometrics strategies, through a Systematic Review. The sample had 86 articles. The results show that 2014 had the highest number of publications, highlighting the authors: Joel Souza Dutra, Elza Fatima Veloso, Leonardo Nelmi Trevisan and Dione Fagundes Nunes Gomes. There is a predominance of female authors (58.17\%). The University of

\footnotetext{
${ }^{1}$ Acadêmica do Curso de Administração do Centro Universitário FAI de Itapiranga (UCEFF), Santa Catarina. E-mail: tamilesprovenzi@gmail.com.

${ }^{2}$ Mestre em Administração pela Universidade do Vale do Itajaí (Univali). Professora titular do Centro Universitário FAl de Itapiranga-SC (UCEFF). E-mail: rosiane.oswald@bol.com.br.
} 
São Paulo (USP) composes the core in the national scenario, with sixteen related articles. The magazine ReCaPe (Journal of Career and People) was the one that published most, with eleven (11) works. Qualitative studies stood out (43.02\%), being the main areas of author's publication interest: Careers, People Management, Work and Skills. For the future, it is suggested studies that address career preparation, talent retention, valorization and professional growth, career anchors, generation " $Y$ " and public management studies. As final considerations are showed the main analyzes, limitations and suggestions that the present work has competence to be instrument for new studies.

Keywords: Career Management. Systematic Review. Scientific Production.

\section{INTRODUÇÃO}

A Gestão de Carreira é um assunto relevante e fundamental aos indivíduos na condição de profissionais e para as organizações. Isso porque é a Gestão de Carreira que propõe um posicionamento à cerca daquilo que planejam e almejam em relação à vida pessoal e profissional.

Dutra (2008) já definia que a Gestão de Carreira é como um processo pelo qual os profissionais desenvolvem, implementam e monitoram metas e estratégias de carreira. Segundo o autor, a otimização desses processos, através de uma gestão estruturada de carreira, resulta em indivíduos mais produtivos e com resultados melhores. Peres (2011) complementa essa definição, ao destacar a importância da continuidade desse processo ao longo do tempo.

Atualmente, com um mercado profissional flexível e competitivo, a Gestão de Carreira é um termo que vem se desenvolvendo constantemente. Além disso, a temática vem sendo trabalhada por grandes pesquisadores da área de Gestão. Nesse sentido, diante do cenário brasileiro, as publicações científicas que abordam o tema gestão de carreira vêm evoluindo continuamente (JUNIOR; SANTANA; 2014). Paixão e Silveira (2017) ainda afirmam que o planejamento da carreira é de responsabilidade de cada indivíduo, e as organizações diante do planejamento de carreira de seus indivíduos, são responsáveis pela Gestão de Carreira.

Sendo assim, esta pesquisa busca delinear o perfil da produção científica do tema Gestão de Carreira nos artigos publicados no Brasil, buscando compreender o perfil e as tendências do campo, a partir da produção científica sobre o tema, por meio da análise dos artigos publicados na base de dados Scientific Periodicals Electronic Library (Spell) e Scientific Electronic Library Online (Scielo), classificados nos respectivos Qualis da Coordenação de Aperfeiçoamento de Pessoal de Nível Superior (Capes). O questionamento a ser respondido pelo esforço de pesquisa é: Qual o perfil das publicações científicas que abordam o tema Gestão de Carreira nos Periódicos Brasileiros?

Observa-se que, no contexto brasileiro, há carência de estudos que sistematizem pesquisas acadêmicas sobre a Gestão de Carreira, não se encontrando qualquer levantamento 
bibliométrico sobre o termo nestas duas bases de dados. Portanto, a importância do estudo está ligada à necessidade de conhecer a evolução conceitual sobre o tema, parâmetros e tendências de publicações. Para tanto, a análise das características da produção científica nacional parece ser um caminho interessante, visto que, de um modo geral, a produção acadêmica tende a acompanhar o comportamento das organizações no contexto da produção.

Neste viés, será apresentada a distribuição da produção científica ao longo do tempo, o número de autores por artigo e os periódicos que mais abordaram e publicaram esse tema. Também será elaborada uma rede de colaboração para a visualização das relações de autoria entre os autores, para que seja possível compreender o nível de cooperação e influência entre autores de diferentes regiões e instituições.

Nesta direção, o trabalho inicia com uma introdução e objetivos, os quais já foram apresentados. Em seguida, apresenta-se o capítulo teórico, no qual são abordados os principais conceitos sobre a Gestão de Carreira e Publicações Recentes na área, e em seguida, a metodologia da pesquisa e na sequência, o resultado da pesquisa. Para finalizar, discutem-se os resultados e são apresentadas as considerações finais e as referências.

\section{REVISÃO DA LITERATURA}

A revisão abrangerá dois tópicos. O primeiro tratará dos principais conceitos sobre a Gestão da Carreira e da evolução do termo carreira. Paradoxo ao primeiro tópico, o segundo discorrerá acerca de estudos recentes sobre a temática.

\section{PRINCIPAIS CONCEITOS E A EVOLUÇÃO DO TERMO GESTÃO DE CARREIRA}

Em tempos mais recentes o termo carreira vem se desenvolvendo e aperfeiçoando nos âmbitos pessoais e profissionais. Chanlat (1995) destaca que a noção do termo carreira é considerada recente, pois a sua eclosão é oriunda no século XIX. Nesse sentido, a ideologia da palavra carreira, advém com a sociedade industrial capitalista. Paradoxo aos tempos de Feudalismo que era uma divisão de sociedade entre Clero, Nobre e Terceiro Estado, a sociedade industrial capitalista era liberal, ou seja, o progresso individual viabilizava a liberdade dos indivíduos.

Por meados dos anos 70 foram várias as mudanças que ocorreram em relação à Carreira. Nesse sentido, para os indivíduos que nascessem em determinadas classes, não havia a segmentação de perspectiva de carreira, nasciam para dar continuidade às classes existentes. Sendo assim, com a inserção na sociedade industrial capitalista, a carreira não está mais subordinada totalmente às classes, sendo o primeiro passo de uma autonomia pessoal (CHANLAT, 1995).

Chanlat (1996) já descrevia que tais avanços foram marcados pela chegada maciça das 
mulheres no mercado de trabalho, avanço da tecnologia e também em relação à economia. Além disso, houve a inserção de grupos sociais no mercado de trabalho e uma forte tendência à progressão descontinuada e à instabilidade. Concomitantemente, Malvezzi (1999) afirma que tradicionalmente a carreira acontecia de forma planejada, e possuía cunho hierárquico. A empresa era quem criava uma trajetória internamente para os trabalhadores. O Autor ainda afirma que essa teoria foi adentrada nas mentes das pessoas, e sendo assim, parte significativa das pessoas acreditam que a trajetória de um trabalhador ainda seja planejada e deva ser seguida dessa maneira.

Peres (2011) relata que as empresas necessitam cada vez mais de profissionais em processo de qualificação em relação à administração de carreira, pois é preciso que a mesma seja vista como um elo entre os indivíduos e a empresa. Junior; Santana (2014) complementam que para se obter profissionais qualificados é preciso que as empresas possuam em seus planos uma gestão de carreira. Essa é uma ferramenta essencial para a obtenção de sucesso para ambas as partes. Isso gerará outros benefícios como: motivação e o aparecimento de talentos, o que gerará resultados desejados no mercado.

Paradoxalmente as citações anteriores, Balassiano e Costa (2006) destacam que nos últimos 20 anos as pesquisas vêm crescendo e ampliando na área de gestão de pessoas, por meio de estudos de seu significado repercussão e alcance. Brandassoli (2009) caracteriza carreira como uma ampla diversidade de definições. De maneira simples, pode ser emprego, salário, vocação, ocupação, trajetória de um indivíduo, posição de uma organização, chegando a um conceito de carreira como mediador capaz de ligar as experiências humanas em torno do trabalho.

Veloso (2009) esclarece que para a construção de uma carreira é preciso atitudes que reflitam nas demais esferas de vida de um indivíduo. Nesse sentido, as adaptações abrangem de um âmbito pessoal, por exemplo, até uma esfera familiar. Já as organizações requerem optar por quadros enxutos e flexíveis, isso para se manterem ativas e competitivas. Sendo assim, surge o termo que tange para carreira sem fronteira, essa que possui habilidades precisas para a movimentação profissional. Dutra (2010) direciona a atenção destacando a carreira como uma mobilidade ocupacional, uma jornada a ser seguida, ou como estabilidade ocupacional, o que vem a representar carreira como profissão.

Tradicionalmente, a carreira é um ajustamento em relação a uma ocupação escolhida. Gomes et al (2011) retratam que há três constantes que limitam em relação à carreira. A primeira e a noção de avanço que está associada a ganhos de remuneração e crescimento como status, ou seja, associar carreira a uma determinada profissão, no sentido de que a profissão de um Médico possui carreira enquanto a ocupação de um operário não é vista como uma profissão de carreira. Por fim, a mesma segmentação de atividades deverá ser realizada, continuamente, até obter aposentadoria. 
Outra concepção vem a partir de Dutra (2008) esclarece que as pessoas necessitam estar em um processo preparatório, pois a cada dia os rumos estão se tornando mais complexos e exigentes. Sendo assim, a trajetória dessas pessoas precisa ser analisada para seu melhor desenvolvimento. Schuster e Dias (2012) afirmam que a utilização dessas ferramentas pode fazer toda a diferença em relação à gestão dos colaboradores e das organizações. O plano de carreira é fundamental para motivar os indivíduos, além de ser uma ferramenta que impõe às claras os objetivos pessoais e organizacionais que vêm ao encontro do alinhamento de carreira para obter sucesso nos resultados dos negócios (FREITAS; JABBOUR, 2010).

De acordo com Bendassoli (2009) a gestão de carreira contribui com a orientação de pessoas e de organizações. A carreira é o resultado de uma construção que os indivíduos edificam suas experiências e dão sequência em relação à vida e ao trabalho. Desta maneira, estes profissionais visam o desenvolvimento donde estão inseridos. Sendo assim, é possível compreender que gestão de carreira é um englobamento do qual envolvem as práticas de gestão de pessoas e de como as empresas definem seus processos dentro da gestão (VELOSO et al, 2011).

Portanto é compreensível de acordo com os autores anteriores que o termo carreira adjunto à gestão de carreira é fundamental para o crescimento e desenvolvimento de indivíduos e de organizações. O planejamento de carreira é um dos primeiros caminhos a serem trilhados para o desenvolvimento de uma jornada. A gestão de carreira é um processo que proporciona aos indivíduos e as organizações uma maior facilidade de segmento de rumos. E o mais atrativo é que as pesquisas e o significado das palavras geram ainda mais buscas em aperfeiçoamento dos termos.

Sendo assim, a seguir será apresentado o que os autores com publicações mais recentes relatam à cerca do tema. Os autores, oriundos de um estudo bibliométrico trazem em pauta as principais considerações em relação ao termo gestão de carreira, suas definições, satisfações e rumos à cerca do tema.

\section{ESTUDOS RECENTES SOBRE A GESTÃO DE CARREIRA}

Na busca por preencher lacunas de pesquisa e a partir de uma análise bibliométrica na base de dados de Spell e Scielo, serão apresentados estudos recentes sobre o tema Gestão da Carreira. Um estudo foi aplicado por Veloso et. al (2014) com jovens universitários na faixa etária entre 18 e 25 anos. A pesquisa foi desenvolvida entre os períodos 2007 e 2012, cujo foco era investigar as âncoras de carreira em concluintes da graduação em Administração. A análise foi realizada por meio de levantamento transversal em duas seções: medida de valores e medidas de expectativas. Os resultados indicaram que a âncora que possuiu maior elevação foi a de "autonomia e independência". Paradoxalmente a âncora "serviço e dedicação a uma causa", ocupou desde a primeira instância a última colocação. E a âncora "estilo de vida" é a 
que se manteve em primeiro lugar.

A associação dos resultados das expectativas com os resultados relacionados aos valores aponta que os respondentes, em sua busca por equilíbrio entre vida pessoal e profissional, manifestam ao longo do tempo, a preferência por valores relacionados às âncoras "estilo de vida" e "autonomia e independência". A amostra realizada por ano procurou refletir, as diferentes visões do mundo do trabalho que, a conjuntura econômica de cada ano oferece aos jovens, em relação às âncoras e a gestão de carreira. Para estudos futuros, os autores sugerem replicar no mesmo público, de forma a identificar se as âncoras mudarão ao longo dos anos (VELOSO et al., 2014)

Silva et al. (2016) realizaram uma pesquisa quantitativa com 189 formandos do curso de Administração de uma universidade comunitária católica da cidade de São Paulo. Para a identificação da ancora de carreira dos respondentes, utilizou-se o instrumento de Schein (1990) e, para os valores, o de Schwartz (1994). Técnicas estatísticas foram utilizadas para explorar as associações entre as âncoras e os tipos motivacionais dos entrevistados.

Diante disso, evidenciou-se que os resultados se remeteram a predominância da Âncora Estilo de Vida, na divisão dos conglomerados, essa Âncora foi característica predominante na diferenciação do conglomerado menor de respondentes, o das novas carreiras. Já a Âncora Gerência Geral, que e a de menor incidência, e a característica predominante na caracterização do conglomerado maior, o das carreiras organizacionais. Além da Âncora Estilo de Vida, o valor Hedonismo foi predominante entre os respondentes. Como sugestão futura, foi constatada a necessidade de relevância do uso de duas formas de análise sobre as orientações das escolhas de carreira da geração Y: as âncoras e os valores, os quais devem ser explorados com maior profundidade em estudos futuros. (SILVA et. al, 2016).

Mais recentemente, Paixão e Silveira (2017) estudaram os gestores de uma organização. O objetivo da pesquisa foi a integração do desenvolvimento individual e organizacional, balizada a partir da gestão estratégica de pessoas e efetivada por meio do sistema de administração da carreira. Foram utilizados métodos como: entrevista semiestruturada, Checklist, Documental e Observação.

Os resultados demonstraram, que os gestores, os líderes e demais responsáveis promovem, no dia a dia, a multiplicação e o repasse dos valores organizacionais. O perfil das lideranças, voltado à formação dos seus sucessores, possibilitou a organização de um corpo funcional que tem se qualificado ao longo dos anos. Além disso, a partir dos resultados é possível concluir que os gestores e líderes conduzem a realização de um trabalho com maior probabilidade de satisfação, envolvimento, comprometimento e, consequentemente, engajamento com propósitos e resultados organizacionais. Diante das análises, foi possível observar que o artigo em tese não possuía sugestões futuras (PAIXÃO E SILVEIRA, 2017)

Silva et. al, (2018) realizaram uma pesquisa com 170 funcionários de empresas 
associadas a Associação Comercial e Industrial de ljuí, norte do Rio Grande do Sul. Foram aplicados três questionários. O primeiro se remete à identificação de perfil sócio demográfico (gênero, idade, escolaridade e afins). O segundo, questões fechadas, tipo Likert de 5 pontos com a última questão aberta com questões referentes à escolha e o que influência e por fim a terceira etapa remete-se a questões de envolvimento e comprometimento com a carreira também do tipo Likert de 5 pontos com 12 questões fechadas.

Como resultado, perfil demográfico da amostra estudada, verificou-se que 60,17\% dos respondentes pertencem à geração Y e $39,83 \%$ são da geração X. Assim como nos motivos da escolha da área de atuação, os motivos pelos quais os trabalhadores do comércio e indústria do município estão comprometidos com a carreira escolhida são os mesmos para ambas as gerações. Nesse sentido como limitação e indicação futura sugere-se que deva ser dada continuidade a esse estudo, expandindo às demais empresas dos setores comercial e industrial de ljuí. (SILVA, et. al, 2018).

Os artigos apresentados indicam que a temática Gestão de Carreira vem evoluindo, mas que ainda apresenta um vasto campo de investigação. Sendo necessário para o avanço da produção científica, como também, para melhorar o desenvolvimento pessoal e organizacional, pois a gestão de carreira é fundamental na construção da trajetória pessoal e profissional. A seguir, serão apresentados os procedimentos metodológicos utilizados no presente artigo.

\section{PROCEDIMENTOS METODOLÓGICOS}

O presente trabalho possui o objetivo de delinear o perfil da produção científica do tema Gestão de Carreira nos artigos publicados na base de dados SPELL e Scielo. Neste sentido, esta pesquisa quanto aos objetivos, caracteriza-se como descritiva. Gil (2008) destaca que a pesquisa descritiva possui o intuito de descrever as principais características de determinados fenômenos e/ou população.

Ao referir-se à abordagem do problema em questão, a pesquisa é de natureza qualitativa. Costa et. al (2018) delinearam as pesquisas qualitativas como algo que busca a compreensão dos mais diversos aspectos de um determinado fenômeno, voltado a explicações mais detalhadas dos casos mais específicos. A operacionalização se deu por meio de uma pesquisa bibliométrica. Os métodos bibliométricos são essenciais, pois é uma valiosa ferramenta, tanto para o estudo das diferentes questões das disciplinas, quanto para a produção científica de um determinado tema (BRUFEM; PRATES 2005). As bases de dados utilizadas foram o Spell e a Scielo. Ao término, realizou-se uma análise semântica, área que estuda o sentido das palavras, com o intuito de averiguar quais pesquisas e áreas do conhecimento foi citada com maior frequência.

A busca pelos artigos ocorreu no dia 06 de março de 2018. O período compreendido 
para a busca ocorreu entre os anos de 2010 a 2018. Tal corte, se justifica por decorrência do número de publicações referente o tema abordadas desde o ano de 1994, devido ao fato de demonstrar os assuntos mais recentes em relação à Gestão de Carreira, optando o presente estudo, explorar as publicações relacionadas ao tema a partir desta última década. Após a leitura dos títulos e resumos, os artigos coletados foram validados e a amostra final ocorreu por meio dos seguintes filtros:

Tabela 1 - Filtros utilizados na amostra.

\begin{tabular}{|c|c|}
\hline Base de dados Scielo & Total de trabalhos \\
\hline Título do Documento "Gestão de Carreira" & 104 \\
\hline Filtros: "Campo" & 72 \\
\hline Coleção: "Brasil" & 47 \\
\hline Idioma: "Português" & 43 \\
\hline Ano de Publicação: "2010 a 2018” & 31 \\
\hline Tipo de Literatura: "Artigos" & 30 \\
\hline Subtotal & 30 \\
\hline Base de dados Spell & Total de trabalhos \\
\hline Título do Documento "Gestão de Carreira" & 193 \\
\hline Filtros: Campo: "Resumo" & 105 \\
\hline Período de Publicação: “2010 a 2018” & 82 \\
\hline Tipos de Documento: "Artigos" & 77 \\
\hline Área de conhecimento: "Administração" & 68 \\
\hline Idioma: Português & 65 \\
\hline Subtotal & 65 \\
\hline Total da amostra & 95 \\
\hline Repetidos & 08 \\
\hline Inglês & 01 \\
\hline Total Geral & 86 \\
\hline
\end{tabular}

Fonte: Elaborado pelas autoras (2018)

Os 95 artigos selecionados foram analisados por meio da análise de conteúdo, de forma que, as informações contidas nos mesmos auxiliassem na estruturação de uma ficha classificatória. Para a realização desta análise, os dados de cada artigo que compuseram a amostra, foram tabulados e lançados em uma planilha eletrônica.

As variáveis que compuseram a planilha foram: (1) distribuição de artigos por ano; (2) distribuição de artigos por evento e autoria; (3) distribuição de autores; e (4) distribuição de autores por instituições, (5) método de pesquisa aplicado pelos autores, (6) principais palavras- 
chaves e (7) indicações de futuros estudos. Para a análise semântica e de conteúdo foram consideradas as palavras-chave, as metodologias apresentadas e as indicações de futuros estudos apontados pelos autores analisados. Esclarecido o processo metodológico, o tópico a seguir, apresentará as análises.

\section{APRESENTAÇÃO E ANÁLISE DOS RESULTADOS}

A análise de resultados foi desenvolvida em duas etapas. A primeira, por meio da análise descritiva do primeiro grupo de variáveis e a segunda, por meio da análise semântica do conteúdo, abrangendo o segundo grupo de variáveis.

\section{ANÁLISES DESCRITIVAS DO ESTUDO BIBLIOMÉTRICO}

De forma inicial, destaca-se que foram analisados 86 artigos. A Tabela 2 apresenta o período evolutivo das publicações sobre o tema em questão:

Tabela 2 - Quantidade de publicações por período

\begin{tabular}{lll}
\hline Ano de publicação & Número de artigos & $\%$ \\
\hline 2010 a 2012 & 24 & 27,91 \\
\hline 2013 a 2015 & 37 & 43,02 \\
\hline 2016 a 2018 & 25 & 29,07 \\
\hline Total & 86 & 100,00 \\
\hline
\end{tabular}

Fonte: Dados da Pesquisa.

Em relação aos anos das publicações, o período de 2013 a 2015 obteve o maior destaque $(43,02 \%)$, sendo trinta e sete artigos publicados. O aumento das publicações pode estar relacionado aos incentivos governamentais gerados pelo governo para aumentar a pesquisa e o aumento do número de Revistas neste período no Brasil (MORAES, 2017). Em seguida, a Tabela 3, apresentada os principais autores com o maior número de publicações: 
Tabela 3 - Autores que mais contribuíram nas pesquisas

\begin{tabular}{|c|c|c|c|c|}
\hline Autor & Titulação & Área de conhecimento IES & $\begin{array}{l}\text { Quant. de } \\
\text { publicações }\end{array}$ & $\%$ \\
\hline Joel Souza Dutra & Doutor & Administração (USP) & 08 & 3,33 \\
\hline Elza Fátima Rosa Veloso & Pós-Doutora & Administração (FEA-USP) & 04 & 1,67 \\
\hline Leonardo Nelmi Trevisan & Pós-Doutor & $\begin{array}{l}\text { Economia do Trabalho } \\
\text { (University of London) }\end{array}$ & 04 & 1,67 \\
\hline $\begin{array}{ll}\text { Dione } & \text { Fagundes Nunes } \\
\text { Gomes } & \end{array}$ & Doutora & $\begin{array}{l}\text { Administração de Empresas } \\
\text { (PUC-SP) }\end{array}$ & 03 & 1,25 \\
\hline $\begin{array}{l}\text { Demais autores com duas } \\
\text { (2) publicações }\end{array}$ & & & 34 & 14,16 \\
\hline $\begin{array}{l}\text { Demais autores com uma } \\
\text { (1) publicação }\end{array}$ & & & 187 & 77,92 \\
\hline$\overline{\text { Total }}$ & & & 240 & 100,00 \\
\hline
\end{tabular}

Fonte: Dados da Pesquisa.

Ao analisar o gênero dos autores que publicam sobre o tema, destaca-se que 58,17\% são do gênero feminino e $41,83 \%$ do gênero masculino. Embora o maior número de publicações seja do público feminino, a discrepância é relativamente pequena, o que pode indicar que o tema Gestão de Carreira é de interesse de ambos os gêneros de pesquisadores.

Quanto aos autores com mais artigos publicados, destaca-se o autor Joel de Souza Dutra (oito publicações), este atua como professor na área de Administração na USP. As principais temáticas que o autor trabalha são: Administração de Recursos Humanos com ênfase em gestão por competência, carreira, gestão de pessoas e desenvolvimento de lideranças. $\mathrm{O}$ autor possui vínculos com alguns periódicos que se destacam: a REGE (Revista de Gestão), ANPAD, e RAC (Revista de Administração Contemporânea) e por fim, o Periódico RAE (Revista de administração de empresas).

Conseguinte, a autora Elza Fátima Rosa Veloso (quatro publicações) é professora de Pós-Graduação no Centro Universitário das Faculdades Metropolitanas Unidas (PPGA/FMU), e, além disso, é pesquisadora em Gestão de Carreira também pela FEA-USP, e já tem assumido vários cargos de coordenação na área da Administração, gestão de pessoas e carreira. Já Leonardo Nelmi Trevisan, também com quatro publicações, é professor na PUC no Departamento de Economia e na Pós-Graduação em Administração, coordena o Grupo de Pesquisa Gestão de Carreiras e Transformação no Trabalho, além disso, é editor em revistas, jornalista e atua como professor na Escola Superior de propaganda e em áreas do mercado de trabalho, economia e relações internacionais.

Por fim, Dione Fagundes Nunes Gomes, atualmente exerce a docência na PUC/SP em áreas da Administração, especialmente com ênfase em Administração de Recursos Humanos, 
atuando no campo do comportamento organizacional, treinamento e desenvolvimento, e gestão de pessoas. Uma vez definido os autores que mais se destacaram, buscou-se verificar as principais publicações científicas construídas em conjunto, apresentadas no quadro 01.

Foi possível perceber que os autores já publicam juntos há um bom período de tempo. Provavelmente esta conexão acadêmica ocorre porque o professor Leonardo Nelmi Trevisan foi orientador da Tese e Dissertação da autora Dione Fagundes Nunes Gomes. Do mesmo modo que nas publicações sequentes, Joel Souza Dutra foi orientador da tese de Elza Fátima Rosa Veloso, o que permitiu que os mesmos construíssem publicações em relação ao tema Carreiras. Já as últimas publicações foram estudos que os autores, por meio da ligação com a PUC/SP e a FEA-USP realizaram com estudantes.

Quadro 01 - Principais Trabalhos dos Autores

\begin{tabular}{|c|c|c|}
\hline Autores & Publicação Científica & Ano \\
\hline $\begin{array}{l}\text { Dione Fagundes Nunes Gomes } \\
\text { Leonardo Nelmi Trevisan }\end{array}$ & $\begin{array}{l}\text { Entre a Âncora de Carreira e a escolha profissional- Análise das } \\
\text { primeiras definições de Carreira dos formandos de } \\
\text { Administração de São Paulo. }\end{array}$ & 2011 \\
\hline $\begin{array}{l}\text { Dione Fagundes Nunes Gomes } \\
\text { Leonardo Nelmi Trevisan }\end{array}$ & $\begin{array}{l}\text { Seriam as Âncoras de carreira aderentes às carreiras } \\
\text { inteligentes? Estudo comparativo entre alunos formados do } \\
\text { Curso de Administração de Empresas e Turismo }\end{array}$ & 2011 \\
\hline $\begin{array}{l}\text { Elza Fátima Rosa Veloso } \\
\text { Joel Souza Dutra }\end{array}$ & $\begin{array}{l}\text { Carreiras sem Fronteiras na Gestão Pessoal da Transição } \\
\text { Profissional: um Estudo com Ex-Funcionários de uma Instituição } \\
\text { Privatizada. }\end{array}$ & 2011 \\
\hline $\begin{array}{l}\text { Elza Fátima Rosa Veloso } \\
\text { Joel Souza Dutra }\end{array}$ & $\begin{array}{l}\text { A tomada de decisões na transição de } \\
\text { carreira: uma proposta de associação de } \\
\text { conceitos. }\end{array}$ & 2014 \\
\hline $\begin{array}{l}\text { Leonardo Nelmi Trevisan } \\
\text { Elza Fátima Rosa Veloso } \\
\text { Joel Souza Dutra }\end{array}$ & $\begin{array}{l}\text { Momento social, valores e expectativas: } \\
\text { como as mudanças econômicas influenciam a visão dos jovens } \\
\text { sobre o trabalho? }\end{array}$ & 2014 \\
\hline $\begin{array}{l}\text { Leonardo Nelmi Trevisan } \\
\text { Elza Fátima Rosa Veloso } \\
\text { Joel Souza Dutra }\end{array}$ & $\begin{array}{l}\text { Âncoras e valores sob diferentes Perspectivas da gestão de } \\
\text { carreira. }\end{array}$ & 2016 \\
\hline
\end{tabular}

Fonte: Dados da Pesquisa.

Por conseguinte, estão apresentadas as Instituições de Ensino com maior destaque se apresentam na Tabela 04: 
Tabela 04 - Publicações por Instituições de Ensino Superior e suas quantidades (IES)

\begin{tabular}{|c|c|c|}
\hline Instituições de Ensino Superior & Quant. de publicações & $\%$ \\
\hline Universidade de São Paulo (USP) & 16 & 10,96 \\
\hline Universidade Federal de Minas Gerais (UFMG) & 06 & 4,11 \\
\hline $\begin{array}{l}\text { Pontifícia Universidade Católica de Minas Gerais } \\
\text { (PUC-MG) }\end{array}$ & 05 & 3,42 \\
\hline Universidade Federal de Santa Catarina (UFSC) & 05 & 3,42 \\
\hline $\begin{array}{l}\text { Fundação Getúlio Vargas Escola de Administração de } \\
\text { Empresas de São Paulo (FVG EAESP) }\end{array}$ & 04 & 2,74 \\
\hline $\begin{array}{l}\text { Pontifícia Universidade Católica } \\
\text { (PUC) SP }\end{array}$ & 04 & 2,74 \\
\hline $\begin{array}{l}\text { Pontifícia Universidade Católica do Rio Grande do Sul } \\
\text { (PUCRS) }\end{array}$ & 04 & 2,74 \\
\hline Universidade de Brasília (UnB) & 04 & 2,74 \\
\hline Universidade Federal do Rio Grande do Sul (UFRGS) & 04 & 2,74 \\
\hline Universidade Federal do Ceará (UFC) & 03 & 2,05 \\
\hline Universidade Federal de Sergipe (UFS) & 03 & 2,05 \\
\hline Instituições com mais de duas (2) publicações & 34 & 23,29 \\
\hline Instituições com uma (1) publicação & 54 & 36,99 \\
\hline Total & 146 & 100,00 \\
\hline
\end{tabular}

Fonte: Dados da Pesquisa.

Fica evidenciado o papel da Universidade de São Paulo - USP, com 16 artigos publicados. A Universidade possui atualmente 177 revistas de diversas áreas do conhecimento, sendo que no presente trabalho obtiveram-se publicações na revista REGE (Revista de Gestão). Destaca-se que os professores com mais publicações possuem vínculo de formação e trabalho com a USP. A USP possui grupos de pesquisa na área de desenvolvimento de carreira, qualidade de vida no trabalho, gestão estratégica de pessoas, entre outras. Correlacionando, o autor destaque dessa pesquisa Joel Souza Dutra possui vínculo com a Instituição por possuir o Grau de Doutor e por exercer docência em Administração. Elza Fátima Rosa Veloso é Pós-Doutora e publicou pela Instituição e é pesquisadora em áreas de Administração. Além disso, há relação entre os mesmos, é de orientador e orientanda.

Com seis publicações a UFMG (Universidade Federal de Minas Gerais) ocupa a segunda classificação. A Universidade possui atualmente 62 periódicos ativos em divergentes áreas do conhecimento e oferece Cursos de Graduação a Pós-Doutorado em diversas áreas do conhecimento, sendo destaque na área das Ciências Sociais Aplicadas. 
Subsequente, a Pontifícia Universidade Católica de Minas Gerais (PUC-MG) e a Universidade Federal de Santa Catarina (UFSC) possuem cinco (5) publicações cientificas sobre o tema. A PUC-MG possui 28 periódicos disponíveis. Além disso, possui grupos e projetos de pesquisas para diferentes áreas de Administração e oferta oportunidades de pesquisas para a produção científica. Abrange formação em Administração até o Pós-Doutorado na área.

A Universidade Federal de Santa Catarina (UFSC) conta com 44 periódicos disponíveis. Abrange a Formação desde a Graduação até o Pós-Doutorado em diversas áreas do conhecimento. A UFSC possui programas de pesquisa em áreas da Administração como Recursos Humanos, estratégias e gestão. A PUC-SP destaca-se por possuir em seu corpo docente os autores destaques Leonardo Nelmi Trevisan e Dione Fagundes Nunes Gomes. Destarte, ao dar continuidade, são evidenciados os principais periódicos que publicaram na área de Gestão de Carreira.

O Periódico Revista de Carreiras e Pessoas (ReCaPe) foi a revista com o maior número de publicações sobre o tema. O periódico possui parceria firmada entre o Grupo de Pesquisa em Gestão de Carreiras e Transformações no Trabalho da PUC-SP com o Grupo de Pesquisas de Gestão de Carreiras da Universidade de São Paulo. Seu foco está em três grandes temáticas, que são: Carreira, Gestão de Pessoas e Capacitação Docente, todas na área de Administração. Outro destaque, com cinco publicações, vem a Revista de Gestão e Secretariado (GeSec). Seu escopo diz respeito às áreas de gestão e de Processos Administrativo-Técnicos das organizações e instituições de ensino.

Tabela 05 - Periódicos com o maior número de publicações

\begin{tabular}{lll}
\hline Periódicos & Quant. de publicações & $\%$ \\
\hline Revista de Carreiras e Pessoas (ReCaPe) & 11 & 12,79 \\
\hline Revista de Gestão e Secretariado (GeSec) & 05 & 5,81 \\
\hline Revista Organizações em Contexto & 03 & 3,49 \\
\hline Revista Pensamento e Realidade & 03 & 3,49 \\
\hline Revista Saúde em Debate & 03 & 3,49 \\
\hline Periódicos com duas (2) publicações & 34 & 39,53 \\
\hline Periódicos com uma (1) publicação & 27 & 31,40 \\
\hline Total & 86 & 100,00 \\
\hline
\end{tabular}

Fonte: Dados da Pesquisa.

Desse modo, fica perceptível que alguns dos autores com maior número de publicações, tiveram seus artigos publicados em periódicos de destaque. Leonardo Nelmi Trevisan e Dione Fagundes Nunes Gomes publicaram no periódico Pensamento e Realidade, Joel Souza Dutra publicou na Revista de Carreira e Pessoas (ReCaPe). 


\section{ANÁLISE SEMÂNTICA E DE CONTEÚDO}

Uma vez realizadas as análises das primeiras variáveis, será apresentado à análise semântica e de conteúdo. Esta análise busca avaliar as grandes áreas de investigação, quais processos metodológicos foram mais usados pelos artigos analisado e a indicação de futuros estudos, que poderá servir de norte para os futuros pesquisadores do tema.

Miguéis et al. (2013) descrevem a utilização das palavras chaves pertenciam um acesso aos conteúdos dos estudos que abrangem as áreas das quais estão envoltos os principais estudos. Além disso, traduz os pensamentos dos autores e acompanha a evolução científica dos conteúdos das publicações. Sendo assim, o Quadro 02 apresentará as principais palavraschaves agrupadas por temas, suas quantidades e o total encontrado. Dessa maneira segue a classificação das palavras chaves.

A partir das análises dos grupos de palavras chaves, foi possível identificar grandes áreas de interesse de publicação pelos autores, destacando: Carreiras, Gestão de Pessoas, Trabalho e Competências. Os resultados sugerem que temas como Planejamento de Carreira, Âncoras de Carreiras, Competências profissionais, Gestão de Carreira e bem-estar profissional, são temas mais explorados pelos autores que investigam esta temática.

\begin{tabular}{|c|c|c|c|}
\hline Palavra-chave & Variações & Quantidade & Total \\
\hline Carreira & $\begin{array}{l}\text { Carreira } \\
\text { Âncora de Carreira } \\
\text { Planejamento de Carreira } \\
\text { Carreiras } \\
\text { Carreira sem fronteiras } \\
\text { Carreira Proteana } \\
\text { Carreira Profissional } \\
\text { Carreira Docente } \\
\text { Carreira no Setor Público } \\
\text { Carreiras Internacionais } \\
\text { Carreiras Organizacionais } \\
\text { Carreira Híbrida } \\
\text { Decisão de Carreira } \\
\text { Gerenciamento de Carreira } \\
\text { Transição de carreira }\end{array}$ & $\begin{array}{l}16 \\
06 \\
04 \\
03 \\
03 \\
02 \\
02 \\
01 \\
01 \\
01 \\
01 \\
01 \\
01 \\
01 \\
01\end{array}$ & 44 \\
\hline Gestão de Pessoas & $\begin{array}{l}\text { Gestão de pessoas } \\
\text { Gestão de Carreira } \\
\text { Gestão Estratégica de RH } \\
\text { Gestão por Competência } \\
\text { Gestão de RH }\end{array}$ & $\begin{array}{l}05 \\
04 \\
01 \\
01 \\
01\end{array}$ & 12 \\
\hline Trabalho & $\begin{array}{l}\text { Trabalho } \\
\text { Força de trabalho } \\
\text { Gestão do Trabalho } \\
\text { Trabalho e família } \\
\text { Mercado de Trabalho } \\
\text { Trabalhador } \\
\text { Bem-estar no trabalho }\end{array}$ & $\begin{array}{l}04 \\
02 \\
01 \\
01 \\
01 \\
01 \\
01\end{array}$ & 11 \\
\hline
\end{tabular}




\begin{tabular}{l|l|l|l}
\hline & Competências & 02 & \\
\cline { 2 - 3 } Competências & Competência profissional & 02 & \multirow{2}{*}{08} \\
& Competências individuais & 01 & \\
& Competência no trabalho & 01 & \\
& Competências organizacionais & 01 & 75 \\
\hline Palavras Analisadas & Competência & 01 & \\
\hline Outras palavras & - & 75 & 303 \\
\hline Total de Palavras Chaves & - & 228 & 303 \\
\hline
\end{tabular}

Fonte: Dados da Pesquisa.

Compreende-se como necessário ampliar os escopos de publicações que trabalham as Gestões Estratégicas nas Empresas, competências individuais e coletivas e a felicidade no trabalho. Esta dimensão permite que seja possível uma agregação de todas as áreas para se definir e chegar a estudos mais completos sobre a Gestão de Carreira. Ao dar sequência, a Tabela 06 traz as principais Metodologias de Pesquisa utilizada pelos estudos investigados.

Tabela 06 - Classificação dos artigos por abordagem metodológica

\begin{tabular}{lcc}
\hline Abordagem & Quantidade & $\%$ \\
\hline Qualitativo & 37 & 43,02 \\
\hline Quantitativo & 24 & 27,91 \\
\hline Quali-Quantitativo & 13 & 15,11 \\
\hline Revisão Teórica & 12 & 13,96 \\
\hline Total & 86 & 100,00 \\
\hline
\end{tabular}

Fonte: Dados da Pesquisa.

De acordo com a pesquisa bibliométrica e com as deferidas análises o presente estudo identificou que as maiores publicações são de abordagem qualitativa, isso porque foram utilizados pelos autores estratégias de pesquisa de Estudo de Caso, Documental, Exploratória, Grupo Focal e Avaliativa. Os estudos que utilizaram a abordagem qualitativa focaram na busca de estudos de aspectos da gestão de carreira em casos como planejamento pessoal e organizacional, gestão de pessoas, âncoras de carreiras, áreas que buscam compreender a trajetória individual e organizacional e também no desenvolvimento de ambas as partes. Por fim, as indicações de estudos futuros são apresentadas no quadro 03: 
Quadro 03 - Agenda de Investigação

\begin{tabular}{|c|c|c|}
\hline Autores & Ano & Indicações Futuras \\
\hline Miano, Vieira & 2012 & Ampliação de pesquisa com o mesmo \\
\hline Veloso; Vidotto; Trevisan; Gomes; Dutra & 2014 & público e/ou em outras instituições sobre Carreira \\
\hline Silva; Trevisan; Veloso; Dutra & 2016 & Pesquisas sobre escolhas de carreira da Geração \\
\hline Sabino; Rocha; Souza & 2017 & Y \\
\hline $\begin{array}{l}\text { Tiepo; Gomes; Sala; Trevisan } \\
\text { Gomes; Sala; Santos; Trevisan } \\
\text { Dante; Arroyo }\end{array}$ & $\begin{array}{l}2011 \\
2011 \\
2017\end{array}$ & $\begin{array}{l}\text { Estudos para construção de carreira e nas âncoras } \\
\text { de carreira. }\end{array}$ \\
\hline $\begin{array}{l}\text { Oliveira; Ckagnazaroff; Silveira; Moraes } \\
\text { Oliveira; Ckagnazaroff; Silveira; Moraes } \\
\text { Nichele; Stefano; Raifur }\end{array}$ & $\begin{array}{l}2012 \\
2013 \\
2015\end{array}$ & $\begin{array}{l}\text { Estudos para verificar a retenção de profissionais } \\
\text { em outras carreiras para a expansão e a valoriza- } \\
\text { cão profissional }\end{array}$ \\
\hline $\begin{array}{l}\text { Costa; Chiuzi; Dutra } \\
\text { Canabarro; Salvagni } \\
\text { Berlato; Corrêa }\end{array}$ & $\begin{array}{l}2013 \\
2015 \\
2017\end{array}$ & $\begin{array}{l}\text { Estudos de gêneros e diversidades populacionais } \\
\text { dos mesmos para inserção no âmbito empresarial } \\
\text { na carreira }\end{array}$ \\
\hline $\begin{array}{l}\text { Freitas; Jabour } \\
\text { Klein; Mascarenhas }\end{array}$ & $\begin{array}{l}2010 \\
2016\end{array}$ & $\begin{array}{l}\text { Estudos futuros para reforçar a importância na } \\
\text { carreira pública e a melhoria na sua gestão }\end{array}$ \\
\hline
\end{tabular}

Fonte: Dados da pesquisa.

A partir da contextualização dos artigos e do mapeamento bibliométrico observou-se importantes sugestões de agendas futuras de pesquisas. De um modo específico, uma das indicações são pesquisas com profissionais de empresas no que tange a retenção de talento, o que os motivam, valorização e aspectos de crescimento profissional.

Quanto aos objetos de pesquisa, identificaram-se vários estudos realizados com acadêmicos, professores e egressos de Graduação. Os estudos sugerem que se prossiga investigando este público, em prol de buscar compreender os anseios e ajudar no discernimento de carreira desses indivíduos. Além disso, em vários estudos se observou a temática "Âncoras de Carreira", estas que foram desenvolvidas por Edegar Shein e que possui importância no processo decisório e no direcionamento da carreira dos indivíduos. Além disso, nas publicações foi possível compreender a necessidade de estudos que enfatizem a geração "Y".

Diante das 86 publicações analisadas, observou-se e foram identificados os possíveis rumos das publicações científicas por meio de análise de diversas variáveis que compuseram um mapeamento sistêmico deste tema. As principais considerações finais, limitações e 
sugestões de novos estudos serão abordadas no próximo tópico.

\section{CONSIDERAÇÕES FINAIS}

O presente estudo objetivou apresentar um mapeamento bibliométrico das publicações de cunho científico em relação à temática Gestão de Carreira. Sendo assim, foi realizado um estudo sistemático dessas publicações científicas em relação ao tema. Foram encontradas ao total para análise, 95 artigos nacionais, sendo que desses 65 foram relativos à base Spell e 30 para a base Scielo, sendo nove (09) excluídos, oito (08) repetidos e um (01) em língua inglesa, totalizando para desenvolvimento 86 artigos.

As variáveis analisadas foram: (1) distribuição de artigos por ano; (2) distribuição de artigos por evento e autoria; (3) distribuição de autores; e (4) distribuição de autores por instituições, (5) método de pesquisa aplicado pelos autores, (6) principais palavras chaves e (7) indicações de futuros estudos. Para a análise semântica e de conteúdo foram consideradas as palavras-chave, as metodologias apresentadas e as indicações de futuros estudos apontados pelos autores analisados.

Diante do exposto, o questionamento a ser respondido pelo esforço de pesquisa é: Qual o perfil das publicações científicas que abordam o tema Gestão de Carreira nos Periódicos Brasileiros? Ao buscar responder o proposto, foi possível observar que o maior número de publicações ocorreu entre os períodos de 2013 a 2015, resultado que pode estar vinculado ao fato de que nesse período, o governo disponibilizou mais verbas para as publicações científicas e houve o aumento do número de Revistas Científicas.

Em relação aos autores, evidencia-se o papel de Joel Souza Dutra. O autor que atualmente é professor de áreas da Administração da Universidade de São Paulo (USP). Além disso, foram mais três autores que obtiveram mais de duas publicações científicas abordadas, sendo eles: Elza Fátima Rosa Veloso, Leonardo Nelmi Trevisan e Dione Fagundes Nunes Gomes. Identificaram-se relações de orientador e orientando entre os autores investigados.

A Universidade de São Paulo (USP) foi a Instituição de Ensino que mais publicou sobre o tema, provavelmente resultado de a Universidade possuir grupos de pesquisa na área de desenvolvimento de carreira. Além disso, dois dos principais autores bases para a construção do presente trabalho, possuem relação com a USP, sendo que Joel Souza Dutra e Professor na Instituição e Elza Fátima Rosa Veloso é pesquisadora em Gestão de Carreira também pela FEAUSP.

Quanto aos periódicos, se destaca a Revista de Carreira e Pessoas (ReCaPe). A mesma que pertence a PUC-SP, possui parceria firmada entre o Grupo de Pesquisa em Gestão de Carreiras e Transformações no Trabalho com o Grupo de Pesquisas de Gestão de Carreiras da USP. Seu foco está em três grandes temáticas, dentre elas, a Carreira. Por se tratar de um 
periódico que possui parceria com a USP, os principais autores desse estudo não possuem publicações nesse periódico.

No que tange as áreas de investigação, destacam-se as principais: Carreira, Gestão de Pessoas, Trabalho e Competências. Os principais temas abordados foram Planejamento de Carreira, Âncoras de Carreiras, Competências profissionais, Gestão de Carreira e o bem-estar profissional. As pesquisas qualitativas se sobressaíram das demais quando o assunto é gestão de carreira. Dentre os métodos de investigação os mais utilizados foram os Estudos de Caso, Pesquisa Exploratória, Pesquisa Documental, Pesquisa Avaliativa, Grupo Focal e o levantamento Survey.

No que tange as agendas de novos estudos, ficou evidenciado a necessidade de pesquisas com profissionais de empresas no que tange a retenção de talentos, o que os motivam, valorização e aspectos de crescimento profissional. Estudos realizados com acadêmicos, professores e egressos de cursos de graduação.

Diante do exposto e mesmo que haja várias possibilidades de aprofundamento de qualquer tópico abordado neste artigo, é importante destacar que há lacunas de estudo que merecem ser destacadas: trabalhar somente artigos nacionais, o uso de duas bases de pesquisa e ainda limitar por década, embora ciente destas limitações, os métodos utilizados e as revisões sistêmicas foram suficientes para alcançar o objetivo da pesquisa.

Por fim, acredita-se que a contribuição deste estudo está no auxílio a futuros pesquisadores, por meio de dados e informações de cunho bibliométrico e sistemático. Além disso, também poderá ser útil para identificar sua evolução como tema em constante agenda, proporcionando deste modo, uma maior perspectiva de abordagens para o desenvolvimento de novas pesquisas.

\section{REFERÊNCIAS}

BALASSIANO, M.; COSTA, I. S. A. da. Gestão de Carreiras: Dilemas e Perspectivas. São Paulo, Atlas, 2006

BENDASSOLLI, P. F. Recomposição da relação sujeito-trabalho nos modelos emergentes de carreira. Revista de Administração de Empresas-RAE, vol. 49 n. 04, p. 387-400, abr/jul. 2009.

BUFREM, L.; PRATES, Y. O saber científico registrado e as práticas de mensuração da informação. Ci. Inf., Brasília, BRASILIA, v. 34, n. 02, p. 09-25, mai./ago. 2005.

CHANLAT, J. F. Quais Carreiras e para qual sociedade?(I). RAE - Revista de Administração de Empresas, São Paulo, v. 35, n. 06, p. 67-75, nov./dez. 1995.

CHANLAT, J. F. Quais Carreiras e para qual sociedade?(II). RAE - Revista de Administração de Empresas, São Paulo, v. 36, n. 01, p. 13-20, jan./mar. 1996. 
COSTA, W. F. et al. Uso instrumentos de coleta de dados em pesquisa qualitativa: um estudo em produções científicas de turismo. Revista Turismo - Visão e Ação - Eletrônica, Rio Grande do Norte, v. 20, n. 01, p. 1-27, jan./abr. 2018.

DUTRA, J. S. (Org.). Gestão de carreiras na empresa contemporânea. São Paulo: Atlas 2010.

DUTRA, J. S. Gestão de Carreira. GV Executiva, São Paulo, v. 07, n. 01, p. 56-61, jan./dez. 2008.

FOLHA DE SÃO PAULO. Brasil aumenta produção científica, mas impacto dos trabalhos diminui. Disponível em: <http://www1.folha.uol.com.br/ciencia/2017/10/1927163-brasil-aumentaproducao-cientifica-mas-impacto-dos-trabalhos-diminui.shtml>. Acesso em: 20 abr. 2018.

FREITAS, W. R. S.; JABBOUR, C. J. C. Rumo à Gestão Estratégica de Recursos Humanos? Estudo de Caso em uma Organização Pública Paulista. Revista de Ciências da Administração, São Paulo, v. 12, n. 26, p. 163-188, jan./abr. 2010.

GIL, R. L. Tipos de pesquisa. Universidade Federal de Pelotas, 2008. 13 slides, color. Disponível em: <https://wp.ufpel.edu.br/ecb/files/2009/09/Tipos-de-Pesquisa.pdf> Acesso em 16 de abril 2018.

GOMES, D. F. N. et al. Entre a Âncora de Carreira e a escolha profissional- Análise das primeiras definições de carreira dos formandos de Curso de Administração em São Paulo.

Revista Pensamento \& Realidade, São Paulo, v. 26, n. 1, p. 1-17, 2011.

LEAL, J. S. As praticas de Gestão de Carreiras e o Comportamento Organizacional: um estudo com trabalhadores residentes em Portugal. 2013. 105 p. Dissertação (Mestrado em gestão de potencial Humano)- Instituto Superior de Gestão, Lisboa, 2013

MIGUÉIS, A. et al. A importância das palavras-chaves dos artigos científicos da área das Ciências Farmaceuticas, depositados no Estudo Geral: estudo comparativo com os termos atribuídos na MEDLINE.. InCID: R.Cien. Inf. e Doc., Ribeirão Preto, v. 4, n. 2, p. 112-125, jul./dez. 2013.

MALVEZZI, S.. Empregabilidade e carreira. Cadernos de Psicologia Social do Trabalho, São Paulo, v. 2, n. 1, p. 55-72, abr./1999.

PAIXÃO, C. R.; SILVEIRA, A. O sistema de administração da carreira profissional em uma organização brasileira: destaque no gerenciamento de pessoas. Revista de Carreira e Pessoas (ReCaPe), V.07, n. 01, p. 422-438, jan/mar 2017

PERES, J. L. P. Gestão de Carreira:uma questão de Autoconhecimento. Convibra Administração, São Paulo, p. 1-18./2011.

SANDRINI JÚNIOR, O. S. Aprimoramento de pessoal a partir de gestão de carreira. 2014. 1-20 p. Projeto (especialista em gestão de qualidade.)- Universidade Federal do Paraná, CuritibaPR, 2014.

SCHUSTER, M. S.; DIAS, V. V. Plano de Carreira nos Sistemas de Gestão Público e Privado: Uma 
Discussão a luz das Teorias Motivacionais. Revista de Administração Imed, Rio Grande do Sul, v. 2 , n. 1, p. 1-17, jun. 2.

SILVA, A. P. D. M. D. et al. Escolha e Comprometimento de Carreira: Percepção de Profissionais das Gerações X E Y. Revista de Carreira e Pessoas (ReCaPe), Rio Grande do Sul, v. 08, n. 01, p. 19-40, mar. 2018.

SILVA, R. C. D. et al. Âncoras e valores sob diferentes perspectivas da gestão de carreira. Revista Brasileira de Gestão de Negócios Review of Business Management, São Paulo, v. 18, n. 59, p. 145-162, jan./mar. 2016.

VASCONCELLOS, V. C.; NEIVA, E. R. Escala de Expectativas de Carreira na Organização:

Desenvolvimento e Evidências de Validade. Psico-USF, Bragança Paulista, Brasilia, v. 21, n. 02, p. 245-257, mai./ago. 2016.

VELOSO, E. F. R. et al. Gestão de carreiras e crescimento profissional. Revista Brasileira de Orientação Profissional, São Paulo, v. 12, n. 1, p. 61-72, jan./jun. 2011.

VELOSO, E. F. R. et al. Momento social, valores e expectativas: como as mudanças econômicas influenciam a visão dos jovens sobre o trabalho?. Organizações em Contexto, São Bernardo do Campo- SP, v. 10, n. 19, p. 279-305, jan./jun. 2014.

VELOSO, E. F.; DUTRA, J. S. Carreiras sem fronteiras na gestão pessoal da transição profissional: um estudo com ex-funcionários de uma Instituição com características de empresa pública. 2009. 523 p. Tese (Doutorado em Administração)- Faculdade de Economia, Administração e Contabilidade, Universidade de São Paulo (USP), São Paulo, 2009.

VELOSO, E. F. R.; DUTRA, J. S. Carreiras sem Fronteiras na Gestão Pessoal da Transição Profissional: um Estudo com Ex-Funcionários de uma Instituição Privatizada. Revista de Administração Contemporânea, RAC, Curitiba, v. 15, n. 5, p. 834-854, set./out. 2011. 